\title{
Resposta e eficiência agronômica em genótipos de milho à adubação nitrogenada no Sul do Pará
}

\author{
Response and agronomic efficiency in maize genotypes to \\ nitrogen fertilization in the south of Pará
}

Weder Ferreira dos Santos ${ }^{1 *}$ (1D), Layanni Ferreira Sodré Santos ${ }^{1}$ (D), Joênes Mucci Pelúzio² (D), Jefferson da Silva Pereira' (10, Igor Morais dos Reis² (1), Rafael Marcelino da Silva² (1)

'Departamento de Bioprocessos e Biotecnologia, Universidade Federal do Tocantins (UFT), Rua Badejós, Lote 7. Chăcaras 69/72, Zona Rural, Caixa Postal 66, 77402-970, Gurupi, TO, Brasil

2Departamento de Agronomia, Universidade Federal do Tocantins (UFT), Rua Badejōs, Lote 7, Chăcaras 69/72, Zona Rural, Caixa Postal 66, 77402-970, Gurupi, TO, Brasil

*autor correspondente

$\square$ eng.agricola.weder@gmail.com
RESUMO: O uso de adubos químicos, além dos riscos de contaminação ambiental, oneram o produtor em relação aos custos de produção na cultura do milho. O presente estudo visa identificar genótipos de milho responsivos e eficientes ao uso do nitrogênio no Estado do Pará. Neste sentido, foram realizados dois ensaios de competição de genótipos de milho no Estado do Pará, no ano de 2018, sendo um sob condições de alta dose de $\mathrm{N}\left(120 \mathrm{~kg} \mathrm{ha}^{-1} \mathrm{de} \mathrm{N}\right)$ e outro sem N $\left(0 \mathrm{~kg} \mathrm{ha}^{-1}\right.$ de N$)$ em cobertura. $\mathrm{O}$ delineamento experimental utilizado em cada ensaio foi de blocos ao acaso com três repetições e nove tratamentos. A característica estudada foi o rendimento de grãos. Empregou-se a metodologia de Fageria \& Kluthcouski para identificar os genótipos eficientes e responsivos ao N. Considerando a eficiência quanto ao uso de nitrogênio os genótipos BR206 e AG 8088, são os mais eficientes. Já em relação à resposta os genótipos AG 1051 e 2B655PW, são os mais responsivos. Os genótipos PR 27D28 e BRS 3036 são eficientes e responsivos à aplicação de $\mathrm{N}$ para rendimento de grãos.

PALAVRAS-CHAVE: Fertilizantes nitrogenados, rendimento, Zea mays.
ABSTRACT: The use of chemical fertilizers, in addition to the risks of environmental contamination, burden the producer in relation to production costs in the maize crop. The present study aims to identify maize genotypes responsive and efficient to the use of nitrogen in the State of Pará. In this sense, two competition trials of maize genotypes were carried out in the State of Pará, in the year 2018, one being under conditions of high $N\left(120 \mathrm{~kg} \mathrm{ha}^{-1}\right.$ of $\left.N\right)$ and another without $N\left(0 \mathrm{~kg} \mathrm{ha}^{-1}\right.$ of $\left.N\right)$ under cover. The experimental design used in each experiment was a randomized complete block design with three replicates and nine treatments. The studied characteristic was grain yield. The methodology of Fageria \& Kluthcouski was used to identify the genotypes efficient and responsive to $N$. Considering the efficiency to the use of nitrogen the genotypes BR206 and $A G 8088$, are the most efficient. In relation to the response, the genotypes $A G 1051$ and $2 B 655 P W$ are the most responsive. Genotypes PR27D28 and BRS 3036 are efficient and responsive to application of $N$ for grain yield.

KEYWORDS: Nitrogen fertilizers, yield, Zea mays.

\section{Introdução}

Dentro dos sistemas de produção agrícola a cultura do milho tem apresentado significativa importância econômica, pois é um dos principais cereais cultivados no Brasil e no mundo, constitui-se como fonte para a alimentação humana e animal, pois diante do aspecto social é considerado como um alimento de baixo custo, devido à viabilidade de cultivo tanto em grande 
como em pequena escala (GALVÃO et al., 2014). O mesmo pode ainda ser utilizado para diferentes fins industriais, inclusive na produção de biocombustíveis (COMPANHIA NACIONAL DE ABASTECIMENTO, 2018).

O milho é o grão mais consumido em escala mundial com um aumento no seu consumo no biênio 2016/17 de 1.036,2 milhões de toneladas, sendo a estimativa de incremento para 2017/18 de 1.065,3 milhões de toneladas (UNITED STATES DEPARTMENT OF AGRICULTURE, 2018). Aliada ao aumento do consumo nos vários setores, a produção de milho a nível mundial vem crescendo (BRASIL, 2018).

Por outro lado, a produção nacional de milho, em 2017/18, ficou concentrada nos estados de Mato Grosso, 29,9\%, Paraná, $16,1 \%$, Goiás, $10,2 \%$ Mato Grosso do Sul, 10,1\%, Minas Gerais $8,2 \%$. Estes estados têm produção estimada de 66,5 milhões de toneladas, e devem contribuir com $74,6 \%$ da produção nacional esperada em 2017/18 que é de 89,2 milhões toneladas. Desse total, 62,9 milhões correspondem ao milho de segunda safra e 26,3 milhões ao milho na primeira safra, com uma produtividade média estimada de $4.967 \mathrm{~kg} \mathrm{ha}^{-1}$ (COMPANHIA NACIONAL DE ABASTECIMENTO, 2018).

Na região norte, o Estado do Pará foi o maior produtor com uma área de 236,0 mil ha plantados na safra 2017/2018, produção de 788,5 mil toneladas e produtividade de $3.341 \mathrm{~kg} \mathrm{ha}^{-1}$, superando os $3.240 \mathrm{~kg} \mathrm{ha}^{-1}$ da safra anterior. A produtividade da cultura do milho na região Norte é baixa principalmente, por causa, das altas temperaturas, da insuficiência de sementes melhoradas de variedades adaptadas às condições de estresses abióticos de ocorrência na região, tais como as variações climáticas e nutricionais e do baixo nível tecnológico empregado pelos produtores (CANCELLIER et al., 2011; CARVALHO \& SOUZA, 2010; SANTOS et al., 2018; SODRE et al., 2017).

Segundo Santos et al. (2018) o milho mostrar-se como uma das culturas mais exigente em nutrientes, principalmente o nitrogênio (N). Visto que, na maior parte das vezes a quantidade presente no solo naturalmente é insuficiente para prover a demanda da cultura, de modo que, a utilização de fontes externas deste nutriente resulta no aumento dos custos de produção (QUEIROZ et al., 2012; GONÇALVES et al., 2016). $\mathrm{O} \mathrm{N}$ tem funções importantes no metabolismo das plantas, pois esse elemento participa de várias rotas metabólicas e da síntese de proteínas, é constituinte de biomoléculas como ATP, NADH, NADPH, ácidos nucléicos e enzimas essenciais que estimulam o crescimento e o desenvolvimento da parte aérea e do sistema radicular, das moléculas de citocromos e da clorifila (MALAVOLTA, 2006).

Além do seu efeito sobre a produtividade (CANCELLIER et al., 2011; CARVALHO et al., 2011; FARINELLI; LEMOS, 2012; KAPPES et al., 2014; QUEIROZ et al., 2012; SANTOS et al., 2017; SANTOS et al., 2018), o N apresenta grande influência em diversas outras características como o diâmetro de colmo, altura de planta, altura de inserção de espiga, comprimento de espiga, diâmetro de espiga, número de fileiras de grãos por espiga, massa de 1000grãos (KAPPES et al., 2014), massa de matéria seca da parte aérea, matéria seca da parte aérea, e na matéria seca dos grãos (CARVALHO et al., 2011), massa de 100 grãos (FARINELLI; LEMOS, 2012). Diâmetro do sabugo, diâmetro do colmo, comprimento de espigas, número de grãos por espiga, número de fileiras por espiga, massa verde de espigas com palha de plantas de milho doce (CARMO et al., 2012).

A obtenção de genótipos com maior eficiência no uso do nitrogênio (EUN) é desejável e importante tanto para a agricultura capitalizada, quanto para aquela de baixo uso de insumos. Uma vez que os desperdícios e a escassez do N podem implicar na geração de problemas econômicos, de saúde pública, ambientais e de segurança alimentar (CARVALHO et al., 2012). Uma alternativa para aumentar a EUN é o melhoramento genético, o qual pode gerar novos genótipos de milho mais produtivos para solos pobres em N (MAJEROWICZ et al., 2002). De acordo com Cancellier et al. (2011), o desenvolvimento de genótipos eficientes no aproveitamento do $\mathrm{N}$ é desejável, podendo viabilizar o cultivo do milho na agricultura de com baixo uso de capital.

Dentro desse contexto, vários pesquisadores têm buscado à obtenção desses genótipos com maior EUN para a cultura do milho (CANCELLIER et al., 2011; CARVALHO et al., 2012; SANTOS et al., 2016). No entanto, faz-se necessário estudos mais aprofundados sobre genótipos de milho eficientes e responsivos ao $\mathrm{N}$ em diferentes níveis de tecnologia, seja para o cultivo na agricultura capitalizada ou não, nas condições de clima e solos no estado do Pará. Diante do exposto o objetivo, é identificar genótipos de milhos mais eficientes e responsivos ao uso do nitrogênio, para rendimento de grãos, no Estado do Pará.

\section{Material e Métodos}

No ano de 2018, ocorreu a realização de dois ensaios de competição de genótipos de milho na propriedade rural Sítio Vitória, localizada no município de Santa Maria das Barreiras, Estado do Pará, sendo um instalado sob condições de alto nitrogênio $\left(120 \mathrm{~kg} \mathrm{ha}^{-1} \mathrm{de} \mathrm{N}\right)$ e um sob baixo nitrogênio $\left(0 \mathrm{~kg} \mathrm{ha}^{-1} \mathrm{de} \mathrm{N}\right)$. A semeadura foi realizada em 8 de Janeiro de 2018.

Em relação ao delineamento experimental empregado, em cada ensaio foi em blocos casualizados com 9 tratamentos e três repetições. Esses tratamentos foram constituídos por 9 genótipos comerciais, sendo assim denominadas: dos híbridos PR27D28, 2B655PW, AG 1051, AG 8088, BRS 3046, BR 206 e as variedades AL BANDEIRANTE, ANHEMBI, e CATIVERDE.

A parcela experimental foi representada por quatro linhas de cinco metros lineares, espaçadas por $0,90 \mathrm{~m}$ entre linhas. Aárea útil da parcela foi representada pelas duas linhas centrais de cada fileira, descartando-se $0,50 \mathrm{~m}$ das extremidades das fileiras.

O sistema de operações realizadas na preparação do solo aconteceu com as etapas de aração, gradagem e sulcamento. Foram efetuados de forma manualmente o plantio das sementes e a adubação no sulco de semeadura.

A adubação de pré-plantio foi realizada utilizando $300 \mathrm{~kg} \mathrm{ha}^{-1}$ de NPK (5-25-15), para todos os ensaios, sendo os demais tratos culturais efetuados assim que se observar necessidade conforme exigência da cultura.

No que diz respeito às adubações nitrogenadas utilizadas em cobertura, foram de 0 e $120 \mathrm{~kg} \mathrm{ha}^{-1} \mathrm{de} \mathrm{N}$, para os ambientes de baixo e alto nitrogênio. 
As doses utilizadas para os dois ambientes de alto e baixo $\mathrm{N}$ correspondem às menores e maiores produtividade de grãos esperadas pela cultura do milho (RIBEIRO et al., 1999).

Os tratos culturais, como controle fitossanitário contra doenças, pragas e plantas daninhas, foram realizados sempre que necessários, de acordo com as recomendações técnicas para a cultura do milho (FANCELLI; DOURADO NETO, 2004).

A adubação em cobertura utilizou uréia como fonte de nitrogênio sendo parcelada em duas aplicações. A primeira ocorreu no estádio vegetativo, quando as plantas tinham emitido (V4 - quarta folha) e a segunda na emissão (V8 - oitava folha).

Nas fileiras de cada parcela experimental foram colhidas todas as espigas quando os grãos atingiram o estádio reprodutivo (R6 - maturação fisiológica). Em seguida, as espigas foram trilhadas e os grãos acondicionados e identificados, cada genótipo, em um único saco de papel, onde foi calculada a massa de grãos de cada parcela corrigida a $13 \%$ de umidade e transformada $\mathrm{em} \mathrm{kg} \mathrm{ha}^{-1}$ para assim obter o rendimento de grãos.

A metodologia sugerida por Fageria e Kluthcouski (1980), foi utilizada para identificar genótipos eficientes quanto ao uso do nitrogênio $(\mathrm{N})$ e responsivos à sua aplicação. Através desta metodologia, a eficiência correspondeu à média de rendimento de grãos em cada genótipo no ambiente com baixo $\mathrm{N}$. Enquanto a resposta à aplicação do $\mathrm{N}$ para cada genótipo resultou da diferença de rendimento dos dois ensaios, dividido pela diferença ente os níveis de $\mathrm{N}$ utilizados em cobertura, nos dois ambientes estudados, usando a seguinte fórmula:

$$
\text { Resposta }(\%)=(R A N-R B N) /(D E N)
$$

RAN = rendimento em alto nível de nitrogênio;

$\mathrm{RBN}=$ rendimento em baixo nível de nitrogênio e;

$\mathrm{DEN}=$ diferença entre as doses aplicadas $\left(\mathrm{kg} \mathrm{ha}^{-1}\right)$.

Foi utilizada a representação gráfica no plano cartesiano para classificar os genótipos. No eixo das abscissas, encontra-se à eficiência no seu uso, enquanto no eixo das ordenadas encontram-se as respostas à sua aplicação. O ponto de origem dos eixos corresponde à eficiência média e resposta média dos genótipos. No primeiro quadrante são representados os genótipos eficientes e responsivos; no segundo os não eficientes e responsivos; no terceiro os não eficientes e não responsivos e no quarto quadrante os eficientes e não responsivos.

No tocante, as médias dos genótipos, ambientes e índices de eficiência e resposta foram comparadas pelo teste de grupos de Scott e Knott (1974), a 5\% de significância, utilizando o programa SISVAR (FERREIRA, 2011).

\section{Resultados e Discussão}

Pelos resultados da análise de variância apresentados na Tabela 1 , verifica-se que houve efeito significativo $(p<0,05)$ para ensaios, genótipos e interação para rendimento de grãos. Esta última indica um comportamento diferencial dos genótipos nos diferentes níveis de adubação.

O coeficiente de variação $(\mathrm{CV})$ foi $6,17 \%$ na Tabela 1 , classificado como baixo, de acordo com Pimentel-Gomes (2009), o que indica uma boa precisão na condução dos ensaios.
As médias de rendimento de grãos dos nove genótipos avaliados apresentaram uma variação de $4.197 \mathrm{~kg} \mathrm{ha}^{-1}$ (AL BANDEIRANTE), na situação de Baixo $\mathrm{N}$ (BN), a $11.019 \mathrm{~kg} \mathrm{ha}^{-1}$ (AG 1051) na situação de Alto N (AN) (Tabela 1). A média de rendimento de grãos dos ensaios é superior tanto em relação à média da região Norte (safra 2016/17 $3.790 \mathrm{~kg} \mathrm{ha}^{-1}$ ) quanto no Estado do Pará (safra 2016/17 3.270 $\mathrm{kg} \mathrm{ha}^{-1}$ ) (COMPANHIA NACIONAL DE ABASTECIMENTO, 2018).

Os genótipos avaliados no ensaio de BN tiveram suas médias variando de $4.197 \mathrm{~kg} \mathrm{ha}^{-1}$ (AL BANDEIRANTE) a $7.264 \mathrm{~kg} \mathrm{ha}^{-1}$ (BR 206) e apresentaram quatro grupos diferentes quanto às médias. $\mathrm{O}$ grupo com a maior média é composto pelos genótipos BR $206\left(7.264 \mathrm{~kg} \mathrm{ha}^{-1}\right)$, AG8088 (7.204 $\left.\mathrm{kg} \mathrm{ha}^{-1}\right)$ e BRS3046 (6.995 $\left.\mathrm{kg} \mathrm{ha}^{-1}\right)$ e o grupo com menor média é constituído por apenas um genótipo o AL BANDEIRANTE (4.197 kg ha-1).

No ensaio de AN, as médias variaram de $6.315 \mathrm{~kg} \mathrm{ha}^{-1}$ (CATIVERDE) a $11.019 \mathrm{~kg} \mathrm{ha}^{-1}$ (AG1051) e proporcionaram quatro grupos de médias para o rendimento de grãos, onde o grupo com a maior média é composto apenas pelo genótipo AG $1051\left(11.019 \mathrm{~kg} \mathrm{ha}^{-1}\right)$ e o grupo com menor média é formado pelos genótipos ANHEMBI (6.493 $\left.\mathrm{kg} \mathrm{ha}^{-1}\right)$, AL BANDEIRANTE (6.437 $\left.\mathrm{kg} \mathrm{ha}^{-1}\right)$ e CATIVERDE (6.315 $\left.\mathrm{kg} \mathrm{ha}^{-1}\right)$.

$\mathrm{O}$ incremento de produtividade no ensaio de AN justifica que há a necessidade de suprimento desse nutriente, pois não suprimento do $\mathrm{N}$ em cobertura afetar negativamente o rendimento de grãos em BN (SANTOS et al., 2018).

Quanto a eficiência da adubação nitrogenada (Figura 1), foram identificados os genótipos PR 27D28, BRS 3046 (Quadrante I) e AG8088 e BR 206 (Quadrante IV) como eficientes à aplicação de N. Considerados assim por terem apresentado rendimento de grãos sob condições de BN maior que a média dos genótipos avaliados neste trabalho, a qual foi de $5.924 \mathrm{~kg} \mathrm{ha}^{-1}$.

Como mostrado ainda na Figura 1, os genótipos 2B655PW e AG 1051(Quadrante II) e PR 27D28 e BRS 3046 (Quadrante I) foram considerados responsivos à aplicação de $\mathrm{N}$, e se destacaram assim por apresentarem resposta maior que a média dos genótipos estudados. Genótipos que se apresentam com alto índice de resposta são interessantes, pois respondem ao incremento do $\mathrm{N}$ quando cultivados em ambientes adequados (SANTOS et al., 2017).

Destaca-se que os genótipos PR 27D28 e BRS 3036 expressos no Quadrante I, além de eficientes foram considerados também como responsivos, ou seja, eficientes porque atingiram boas produtividades na falta de adubação e responsivos, porque com a adubação nitrogenada, elevaram com significância sua produtividade (SANTOS et al., 2018). Segundo Fidelis et al. (2014), genótipos considerados eficientes e responsivos são recomendados para cultivos agrícolas que adotam desde o baixo até o alto nível tecnológico.

No Quadrante II observa-se que os genótipos AG 1051 e 2B655PW foram caracterizados como responsivos, mas por apresentarem baixo rendimento de grãos em $\mathrm{BN}$ são considerados como não eficientes. Estes genótipos responsivos e não eficientes são indicados para serem utilizados pelos produtores que dispõem de um alto nível tecnológico (SANTOS et al., 2018). 


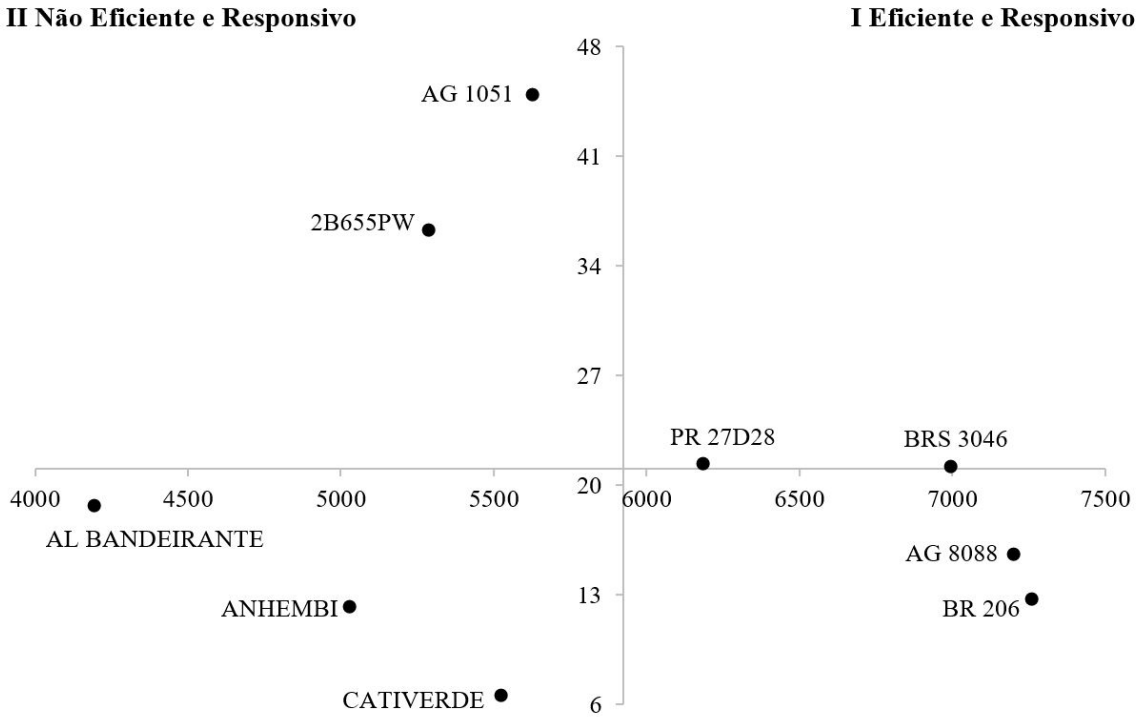

III Não Eficiente e Não Responsivo

IV Eficiente e Não Responsivo

Figura 1. Eficiência no uso e resposta à aplicação de nitrogênio em genótipos de milho, nas condições de clima e solos do estado do Pará.

Tabela 1. Médias de rendimento de grãos $\left(\mathrm{kg} \mathrm{ha}^{-1}\right)$ de nove genótipos de milho cultivados sob dois níveis de N, no estado do Pará.

\begin{tabular}{|c|c|c|c|c|c|c|}
\hline \multirow{2}{*}{$\begin{array}{c}\text { Genótipo } \\
\text { PR 27D28 }^{1}\end{array}$} & \multicolumn{2}{|c|}{ Baixo $\left(0 \mathrm{~kg} \mathrm{ha}^{-1}\right) \mathrm{N}$} & \multicolumn{2}{|c|}{ Alto $\left(120 \mathrm{~kg} \mathrm{ha}^{-1}\right) \mathrm{N}$} & \multirow{2}{*}{$\begin{array}{c}\begin{array}{c}\text { Diferença de } \\
\text { produção }\end{array} \\
2564\end{array}$} & \multirow{2}{*}{$\begin{array}{c}\text { Resposta } \\
21,36\end{array}$} \\
\hline & 6186 & Bb & 8750 & Ac & & \\
\hline 2B655PW' & 5288 & Bc & 9646 & $\mathbf{A b}$ & 4358 & 36,31 \\
\hline AG $1051^{1}$ & 5630 & Bc & 11019 & Aa & 5389 & 44,91 \\
\hline AG 8088 ${ }^{1}$ & 7204 & $\mathbf{B a}$ & 9073 & Ac & 1869 & 15,57 \\
\hline AL BANDEIRANTE ${ }^{2}$ & 4197 & Bd & 6437 & Ad & 2240 & 18,67 \\
\hline ANHEMBI $^{2}$ & 5029 & Bc & 6493 & Ad & 1464 & 12,20 \\
\hline BR $206^{1}$ & 7264 & Ba & 8793 & Ac & 1529 & 12,74 \\
\hline BRS 3046 ${ }^{1}$ & 6995 & Ba & 9526 & $\mathbf{A b}$ & 2532 & 21,10 \\
\hline CATIVERDE $^{2}$ & 5523 & Bc & 6315 & Ad & 792 & 6,60 \\
\hline Média & 5924 & B & 8450 & $\mathbf{A}$ & 2526 & 21,05 \\
\hline CV (\%) & & & 6,17 & & & \\
\hline
\end{tabular}

${ }^{1}$ Híbridos; ${ }^{2}$ Variedades. Médias seguidas por mesma letra minúscula na coluna e maiúscula na linha, pertencem a um mesmo grupo, pelo critério de agrupamento de Scott e Knott (1974), a 5\% de significância.

Os genótipos AL BANDEIRANTE, ANHEMBI e CATIVERDE são considerados como não eficientes e não responsivos (Quadrante III), por terem apresentado baixo rendimento de grãos, com média inferior à média dos genótipos avaliados $\left(7.187 \mathrm{~kg} \mathrm{ha}^{-1}\right)$ e também por terem apresentado baixos índices de resposta $(21,05)$ à aplicação de $\mathrm{N}$ quando comparado à média do referido grupo de genótipos. Genótipos classificados como não responsivos e não eficientes não são indicados para serem utilizados em quaisquer propriedades agrícolas (SANTOS et al., 2018).

No Quadrante IV os genótipos AG 8088 e BR 206 apresentaram alto rendimento de grãos em $\mathrm{BN}$ e baixo índice de resposta à aplicação de $\mathrm{N}$, sendo considerados eficientes e não responsivos. Os genótipos que apresentam este comportamento são recomendados para propriedades que adotam baixo nível tecnológico (SANTOS et al., 2016).

\section{Conclusões}

Considerando a eficiência ao uso de nitrogênio os genótipos BR206 e AG 8088, se comportaram como os mais eficientes. Já em relação à resposta ao uso do nitrogênio, os genótipos AG 1051 e 2B655PW, foram os mais responsivos.

Os genótipos PR 27D28 e BRS 3036 se mostraram eficientes e responsivos à aplicação de nitrogênio para rendimento de grãos.

\section{Referências}

BRASIL. Ministério da Agricultura Pecuária e Abastecimento. Milho em grãos. Brasília, 2018. Disponível em: $<$ http://www.agricultura. gov.br/assuntos/politica-agricola/todas-publicacoes-de-politicaagricola/sumarios-executivos-de-produtos-agricolas/milho.pdf/ view>. Acesso em: 22 out. 2018. 
CANCELLIER, L. L. et al. Eficiência no uso de nitrogênio e correlação fenotípica em populações tropicais de milho no Tocantins. Revista Ciência Agronômica, Fortaleza, v. 42, n. 1, p. 139-148, 2011.

CARMO, M. S. et al. Doses e fontes de nitrogênio no desenvolvimento e produtividade da cultura de milho doce (Zea mays convar. saccharata var. rugosa). Bioscience Journal, Uberlândia, v. 28, n. 1, p. 223-231, 2012.

CARVAlhO, H. W. L.; SOUZA, E. M. Ciclos de seleção de progênies de meios-irmãos do milho BR 5011 Sertanejo. Pesquisa Agropecuária Brasileira, Brasília, v. 42, n. 6, p. 803-809, 2010.

CARVALHO, R. P. et al. Desempenho de cultivares de milho quanto à eficiência de utilização de nitrogênio. Revista Brasileira de Milho e Sorgo, Sete Lagoas, v. 10, n. 2, p. 108-120, 2011.

CARVALHO, R. P. et al. Eficiência de cultivares de milho na absorção e uso de nitrogênio em ambiente de casa de vegetação. Semina: Ciências Agrárias, Londrina, v. 33, n. 6, p. 2125-2136, 2012.

COMPANHIA NACIONAL DE ABASTECIMENTO - CONAB. Acompanhamento da safra brasileira de grãos - Safra 2017/18, - Décimo Levantamento. Brasília, 2018. Disponível em: <http:// www.conab.gov.br>. Acesso em: 19 out. 2018.

FAGERIA, N. D.; KLUTHCOUSKI, J. Metodologia para avaliação de cultivares de arroz e feijão para condições adversas de solo. Brasília: EMBRAPA/CNPAF, 1980. 22 p.

FANCELli, A. L.; DOURADO NETO, D. Produção de milho. 2. ed. Piracicaba: Livroceres, 2004. 360 p.

FARINELLI, R.; LEMOS, L. B. Nitrogênio em cobertura na cultura do milho em preparo convencional e plantio direto consolidados. Pesquisa Agropecuária Tropical, Goiânia, v. 42, n. 1, p. 63-70, 2012.

FERREIRA, D. F. Sisvar: a computer statistical analysis system. Ciência e Agrotecnologia, Lavras, v. 35, n. 6, p. 1039-1042, 2011.

FIDELIS, R. R. et al. Classificação de populações de milho quanto a eficiência e resposta ao uso de fósforo. Pesquisa Agropecuária Pernambucana, Recife, v. 19, n. 2, p. 59-64, 2014.

GALVÃO, J. C. C. et al. Sete décadas de evolução do sistema produtivo da cultura do milho. Ceres, Viçosa, v. 61, n. 7, p. 819-828, 2014.

GONÇALVES, A. K. D. A. et al. Manejo de adubação nitrogenada em milho solteiro e em consorciado com Brachiaria ruziziensis. Revista Brasileira de Milho e Sorgo, Sete Lagoas, v. 15, n. 2, p. 318-327, 2016.
KAPPES, C. et al. Manejo do nitrogênio em cobertura na cultura do milho em sistema plantio direto. Revista Brasileira de Milho e Sorgo, Sete Lagoas, v. 13, n. 2, p. 201-217, 2014.

MAJEROWICZ, N. et al. Estudo da eficiência de uso do nitrogênio em variedades locais e melhoradas de milho. Revista Brasileira de Botânica, São Paulo, v. 25, n. 2, p. 129-136, 2002.

MALAVOLTA, E. Manual de nutrição mineral de plantas. Piracicaba: Editora Ceres, 2006. 631 p.

PIMENTEL-GOMES, F. Curso de Estatística Experimental. 15. ed. Piracicaba: FEALQ, 2009. 451 p.

QUEIROZ, A. M. et al. Avaliação de diferentes fontes e doses de nitrogênio na adubação da cultura do milho (Zea mays L.). Revista Brasileira de Milho e Sorgo, Sete Lagoas, v. 10, n. 3, p. 257-266, 2012.

RiBEIRO, A. C.; GUIMARÃES, P. T. G.; AlVAREZ, V. V. H. Recomendação para o uso de corretivos e fertilizantes em Minas Gerais: $5^{\text {a }}$ aproximação. Viçosa: UFV, 1999. 359 p.

SANTOS, W. F. et al. Eficiência e resposta ao uso do nitrogênio em genótipos de milho para rendimento de proteína. Tecnologia $\&$ Ciência Agropecuária, João Pessoa, v. 10, n. 4, p. 6-11, 2016.

SANTOS, W. F. et al. Resposta e eficiência ao nitrogênio para rendimento de grãos em genótipos de milho. Revista Tecnologia \& Ciência Agropecuária, João Pessoa, v. 12, n. 3, p. 25-30, 2018.

SANTOS, W. F. et al. Resposta e eficiência ao uso do nitrogênio em genótipos de milho tropicais. Revista Tecnologia \& Ciência Agropecuária, João Pessoa, v. 11, n. 4, p. 7-12, 2017.

SCOTT, A. J.; KNOTT, M. A cluster analysis method for grouping means in the analysis of variance. Biometrics, Washington, v. 30, n. 3, p. 507-512, 1974.

SODRÉ, L. F. et al. Genetic divergence in maize under low and high nitrogen for protein and oil production. Pesquisa Agropecuária Pernambucana, Recife, v. 22, n. 1, p.1-7, 2017.

UNITED STATES DEPARTMENT OF AGRICULTURE - USDA. Grain: World markets and trade, 2018. Disponível em: $<$ https:// apps.fas.usda.gov/psdonline/circulars/grain-corn-coarsegrains.pdf $>$. Acesso em: 26 out. 2018.

Recebido: 14 nov. 2018 Aprovado: 01 abr. 2019 